Fernando Guilherme Tenorio, é professor e coordenador dá área de Técnicas de Análise Organizacional da Escola Interamericana de Administração Pública (EIAP) da Fundação Getúlio Vargas.

\title{
Weber e a burocracia
}

1 "Sobre o princípio que deu origem a divisão do trabalho. Esta divisão do trabalho, da qual derivam tantas vantagens, não foi originariamente provocada pelo gênio humano, prevendo com intencionalidade a riqueza que ela viria proporcionar. Foi a conseqüência necessária, se bem que lenta e gradual, de uma determinada tendência da natureza humana que tem como objetivo uma utilidade menos extensiva: a tendência para negociar e trocar uma coisa por outra.

... a troca nos permite obter uns dos outros a maior parte dos serviços recíprocos de que necessitamos; foi ainda essa propensão para a troca que originariamente provocou a divisão do trabalho". SMITH, Adam. Investigaçð̋es sobre a natureza e as causas da riqueza das naçøes. Os Pensadores, São Paulo, Abril Cultural, v. 28, livro I, cap. II, \author{
"O futuro pertence à burocracia..."
}

\section{Introdução}

O fenômeno burocrático manifestou-se praticamente ao iniciar-se a divisão do trabalho1 ou com o chamado 'modo de producão asiático': aqui, certas circunstâncias como falta de água que tornou necessária a irrigação, ou excesso de água, que exigiu esforços para drenar os solos inundados, fez com que surgisse a necessidade de um trabalho coordenado para atender tais situaç̃es. Porém, a teorização do fenômeno burocrático aparece em épocas relativamente recentes, iniciando-se de modo mais sistematizado ao final do século XVIII, que é quando se cria o neologismo 'burocracia'.

A expressão 'burocracia' (bureaucratie no original francês) deriva-se de bureau e este de bure (em latim, pano de lã). Este pano de toalha cobria a mesa na qual se despachavam os negócios oficiais passando-se a utilizar mais tarde a mesma raiz para designar qualquer móvel sobre o qual se escrevia de forma habitual; o passo seguinte foi designar com o mesmo nome o local aonde se encontrava a mesa que se utilizava para escrever.

Bureau deu origem a outro neologismo que foi buraliste, utilizado já no século XVII e passando a significar no século XVIII certas categorias concretas de empregados que atuavam tanto a nível de Governo quanto a nível de empresa privada. É no século XIX entretanto que o fenômeno burocrático passa a ser objeto de análise mais sistematizada. Tal análise partiu de dois grandes movimentos políticos da época - o liberalismo e o marxismo, que apesar de serem proposiçøes opostas, criticam asperamente o Estado, isto é, a burocracia.

No entanto, é Max Weber o teórico que, já no século XIX, ten- 
2. THOMPSON, Victor A. Moderna organizaçăo. Rio de Janeiro, USAID, 1967. Cap. VIII, p. 143-66 tará explicar e desenvolver de maneira imparcial o pensamento burocrático. Surgirá também a melhor definição da expressão burocracia: estrutura de poder hierarquizada segundo a qual certos indivíduos - os burocratas - participam ou executam as decisర̃es de uma organização (seja pública ou privada), graças à sua qualidade de manipuladores de um determinado sistema de gestão, chamado burocrático. Assim, a palavra 'burocracia' refere-se em uma primeira aproximação a três fenômenos distintos: estrutura de poder, sistema de gestão e grupo social, cada um dos quais podendo ser analisado por enfoques ou disciplinas diferentes. Tal circunstância, agravada pelo fato que nem todos os autores têm consciência da complexidade do objeto observado, explica a desarticulação bibliográfica existente em torno do assunto.

Normalmente, tem-se a sensação de que a literatura a respeito do fenômeno burocrático trata de fenômenos completamente distintos, o que nos leva a perguntar até que ponto é lícito falar de burocracia no singular e não de burocracias no plural, já que tantas são as perspectivas científicas que apareceram sobre o tema. $E$ mais ainda, não faltam autores que vêem na burocracia o centro que polariza e dota de coerência a civilização de nosso dias chamada significativamente de civilização burocrática, já que acreditam que a tendência a organizar ou a colaborar de forma interdependente é inerente à natureza humana. Hoje, portanto, a atividade organizada variaria dentro de um contínuo que vai desde os grupos não formais, ad-hoc, até as organizações formais e altamente estruturadas.

Entretanto, essa possível desarticulação bibliográfica não impede que o estudo do pensamento burocrático - quer dizer, a determinação de um quadro referencial anterior à análise de qualquer fenômeno burocrático - deixe de ser imprescindível. Graças a ele pode-se dar sentido a uma realidade universal que é desconhecida em seu caráter global, posto que, como dissemos acima, os estudos são atomizados resultando, portanto, contraditórios.

\section{Antiburocratismos}

A maior parte das obras dedicadas ao estudo da burocracia estão presididas por uma inequívoca mentalidade crítica, ou seja, são antiburocráticas. Essas atitudes coincidem ademais com o pensamento do homem da rua ou contribuinte normalmente insatisfeito - quando não decididamente inimigo - dos burocratas e do que eles representam. Atitude muitas vezes compreensível, dada a proverbial ineficiência da administração pública e, sobretudo, dos modos autoritários ou patológicos2 que adotam os burocratas ao relacionarem-se com o cidadão a quem aborrecem com exigências freqüentemente carentes de sentido.

A que se deverá então a literatura antiburocrática? A simples contaminação da mentalidade popular? Ao ressentimento pessoal de alguns indivíduos dos quais a burocracia despojou dos privilégios, fazendo-os sentir o peso da igualdade, isto é, da impessoalidade preconizada pelo sistema burocrático? Evidentemente que não, ainda que em algumas ocasiőes tal situação ocorra. Porém, o que realmente acontece é que, desde o primeiro momento, os autores têm compreendido que a burocracia é um fenômeno de importante 
3. SMITH, Adam. Investigação sobre a natureza e as cauSas da riqueza das naç̃es. Os Pensadores. São Paulo, Abril Cultural, 1973.

4. MILL, John Stuart. Da liberdade. São Paulo, IBRASA, 1963. Cap. V, p. $123-5$. transcedência política e social e que, como tal, por ser um fenômeno social, presta-se a observações de natureza variada e estudos ideologicamente contraditórios.

Apesar da anterioridade do fenômeno burocrático é fato que somente a partir do século XIX passa a se produzir ampla literatura a respeito. Foram dois os juízos de valor político que orientaram o estudo do pensamento burocrático: os liberais por um lado, combatendo a burocracia por entenderem as atividades estatais como uma ameaça frente à sociedade civil, e os marxistas por outro, desenvolvendo a idéia de que a burocracia está a serviço do Estado burguês. Entretanto, não é através da perspectiva do liberalismo ou do marxismo que devemos iniciar o estudo do pensamento burocrático, pois foi já a partir do século XVIII que se iniciou o processo de formação do Estado burocrático prussiano (Beamtenstaat), sob o reinado de Frederico Guilherme I (1713-1740), com características pecualiares que caracterizaram de forma contundente o fenômeno burocrático; não esquecer também que no começo do período Sung 1960 d.C.) o mesmo fenômeno já era realidade na China. Apesar de reconhecermos a importância desses antecendentes históricos, o nosso trabalho focalizará somente o liberalismo e o marxismo dado que nossa proposta de trabalho é a de apresentar essas duas principais ideologias antiburocráticas. Posteriormente desenvolveremos o 'tipo ideal' weberiano de burocracia, que acreditamos ser de caráter universal e onde podemos encontrar características marcantes do modelo de Estado burocrático chinês e prussiano.

\section{Abordagem liberal}

Sob o ponto de vista liberal, os autores, enquanto políticos liberais e apoiados em argumentos políticos e econômicos, reprovam o Estado não-liberal, isto é, aquele que se deixou dominar por burocratas que, abandonando os critérios liberais, atuam com sistemas diferentes de gestão. Ademais o burocrata, segundo o mesmo juízo, fomenta essa tendência: o Estado intervencionista (antiliberal) fomenta a burocracia, e a burocracia fomenta, por sua vez, o intervencionismo. Tal quadro contrariava as idéias do primeiro ideólogo do liberalismo econômico, Adam Smith (1723-90) 3.

Frente então ao intervencionismo estatal, os liberais exigem que os negócios públicos estejam nas mãos de leigos e não de burocratas profissionais, já que assim não só se libera a sociedade do intervencionismo estatal mas tem-se a segurança de que esses leigos - ainda que seja pelo simples fato de não dominarem as técnicas burocráticas de gestão - atuarão de acordo com os sistemas liberais, isto é, inibindo o Estado em favor da sociedade civil.

O liberalismo, enquanto ideologia política, vai encontrar em John Stuart Mill (1808-73), um defensor férreo do não-intervencionismo estatal. Em sua obra política mais importante, Da liberdade4, diz textualmente Mill:

"As objeçð̋es à interferência do governo, quando não chegam a implicar em infração da liberdade, podem ser de três espećies:

A primeira é quando o que há a fazer provavelmente o farão melhor os indivíduos do que o governo.

... Este princípio condena as interferências, outrora tão comuns, da legislação ou de funcionários do governo, nos processos correntes da indústria... 
5. In SWINGEWOOD, Alam. Marx e a teoria social moderna. Rio de Janeiro, Civilização Brasileira, 1978. p. 178-9.
A segunda objeção... Em muitos casos, embora os indivíduos talvez não realizem tão bem o que se tem em vista, como os funcionários do governo, seria de desejar que o fizessem aqueles, de preferência a estes, como elemento da própria educação mental...

A terceira razão, a mais convincente de todas, no sentido de limitarse a interferência governamental, refere-se ao grande mal de acrescer-lhe o poder sem necessidade. Cada função que se acrescenta às que o governo já exerce provoca maior difusão da influência que Ihe cabe sobre esperanças e temores, convertendo, cada vez mais, a parte ativa e ambiciosa do público em parasitos do poder público, ou de qualquer partido que aspire ao poder..."

Portanto, sob o ponto de vista político, os liberais opõem o Estado à sociedade, desenvolvendo a idéia de que a gestão burocrática desencoraja o processo democrático ou a aprendizagem do dito processo.

\section{Abordagem marxista}

Da mesma forma que o liberalismo condena a interferência do Estado na sociedade, os marxistas também o fazem, claro que não de maneira similar. Karl Marx (1818-94), criticando os Princípios de filosofia do direito de G.W.F. Hegel (1770-1831), refuta a tese hegeliana segundo a qual a burocracia exercia uma função mediadora entre os diversos grupos sociais, agindo desse modo como 'classe universal' no interesse de todos. Segundo Marx, a burocracia encorajava oligarquicamente as divisర̃es políticas indispensáveis à sua própria sobrevivência, perseguindo portanto seus próprios fins em detrimento dos fins da comunidade. Apesar de que, quando Hegel em 1821 publicou os Princípios, estabeleceu o funcionamento do Estado onde o recrutamento dos funcionários, que estariam encarregados de decidir o interesse geral, seria feito em função de suas competências e não por imposição de forças oligárquicas. dizia:

Continuando sua crítica à filosofia do direito de Hegel, Marx

"O espírito geral da burocracia é o segredo oficial, o mistério sustentado dentro da própria burocracia pela hierarquia e mantido no lado de fora como uma corporação fechada. Conduzir os negócios do Estado em público, mesmo a consciência política, parece assim para a burocracia como alta traição contra o mistério. A autoridade é, portanto, o princípio de seu conhecimento, e a deificação do autoritarismo é seu credo... dentro da burocracia o espiritualismo se torna um materialismo crasso, o materialismo da obediência passi$\mathrm{va}$, da fé na autoridade, do mecanismo das atividades rigidamente formais, princípios, pontos de vista e tradiç̋̃es fixos... O burocrata vê o mundo como um mero objeto a ser dirigido por ele." 5

Para Marx, a dominação burocrática da sociedade numa economia capitalista é também uma expressão da alienação, um complemento necessário à dominação do capital sobre a força de trabatho do homem na qual relaçð̃es sociais se tornam relaç̃̃es das coisas; o modo burocrático de gestão reflete a disciplina e o rigor associado à arregimentação capitalista do trabalho, uma administração repressiva e desumanizada dos homens como 'coisas'.

Portanto, da mesma maneira que a hostilidade dos liberais frente ao Estado intervencionista traduz-se em hostilidade frente à 
burocracia, os marxistas, por razões exatamente contrárias às dos liberais, se declaram contra a burocracia, enquanto esta é servidora do Estado burguês. Dito com outras palavras: se rechaça a burocracia por entender que potencia um Estado cuja orientação contradiz as pautas políticas marxistas. Isto é, o Estado burguês, para consolidar sua dominação classista, precisa de uma burocracia; o Estado operário, por outro lado, movido por outras pautas de conduta política, já não precisaria do instrumento burocrático e de seu correspondente sistema de gestão.

Dessa maneira, o destino do Estado estaria íntimamente unido ao da burocracia. Ao menos, assim o vêem, ainda que por motivos diferentes, os liberais e os marxistas. Porém se isto é certo, não é a proposição inversa, ou seja, que não seria lícito afirmar que a burocracia está indiscutivelmente unida ao Estado burguês e somente a ele. A melhor prova disso é o que acontece nos chamados 'estados socialistas' de hoje, onde a burocracia atua com grande vigor talvez até impedindo a consolidação do estado socialista ideal preconizado pelos doutrinários.

A crítica antiburocrática é conseqüência de sua identificação com o Estado, que é, no fundo, o que se combate. A burocracia assume o papel de 'bode expiatório' dos pecados que comete o Estado que fica por cima de todas as críticas. O Estado capitalista é 'perfeito' e seus erros notórios não são imputáveis a ele, mas sim à burocracia imperfeita que a ele serve. E a crítica antiburocrática dos autores marxistas não ortodoxos está dirigida ao fato de o Estado não ser socialista mas sim burocrático. Tal crítica é pois uma crítica ao chamado socialismo estatal.

Por sua parte, os marxistas ortodoxos ou oficiais também dirigem duras críticas à burocracia, ainda que com um sentido totalmente diferente. Para eles a burocracia, como em determinados setores capitalistas, serve de tela protetora das intangíveis instituiçð̋es políticas, fazendo-se responsável exclusiva pelas deficiências dos sistemas que não podem dissimular. O Estado e a linha política não são nunca culpadas. Os defeitos provêm dos burocratas executores, estes expostos a degolas periódicas, em sua condição de tais, para salvar a imunidade dos dirigentes políticos. Assim, a crítica antiburocrática não somente é lícita como também, em algumas ocasiőes, fomentada, já que graças a ela encontra para o mal-estar popular uma saída - considerada psicologicamente recomendável que não põe em perigo a Nomeklatura no dizer do professor Mikhail Voslenki em livro já editado em alemão e francês. A prática disso pode ser identificada quando o presidente e secretário-geral do PC da URSS, Leonid Brejnev, criticou energicamente a falta de competência dos administradores das empresas estatais, acusando-os de burocratismo, insensibilidade e arrogância, relacionando o fato à falta de abastecimento de gêneros de primeira necessidadeà população russa.

\section{O 'tipo ideal'weberiano}

Visualizar o pensamento burocrático através da ótica liberal ou marxista é estabelecer a análise entre dois pólos excludentes. Entretanto, preenchendo as lacunas entre os dois extremos coexistem disciplinas, notadamente aquelas dedicadas ao estudo dos fenômenos sociais nas suas distintas manifestaçð̃es, e que têm como 
objeto de estudo aspectos da burocracia. Dizemos aspectos já que, na realidade, é a perspectiva de cada uma dessas áreas do conhecimento humano parte de um dado sistema burocrático. O resultado tem sido uma imagem caleidoscópica da burocracia: não há como precisar se se trata de um só ou de vários objetos de estudo, o que pode produzir, indubitavelmente, resultados muito variados segundo a metodologia usada. A burocracia de que fala John Stuart Mill é a mesma de Robert Michels ou de Nicos Poulantzas? Eles somente partem da constatação de um fenômeno real, a burocracia . Não há a preocupação em saber se o conteúdo desse fenômeno coincide ou não com o dos outros autores. Alguns procederam de outra maneira. O caso mais conhecido é o de Max Weber que procura adotar uma atitude metodológica neutra, tentando eliminar assim de sua obra os juízos de valor ou ideológicos no estudo do fenômeno burocrático.

Max Weber (1864-1920), sociólogo alemão, concebe a sociologia como 'a captação dả relação de sentido' da ação humana. Em outras palavras, conhecer um fenômeno social (o fenômeno burocrático por exemplo) seria extrair o conteúdo simbólico da ação ou açס̃es que o configuram. Por ação, Weber entende "aquela cujo sentido pensado pelo sujeito ou sujeitos é referido ao comportamento dos outros, orientando-se por ele o seu comportamento".

O método compreensivo, defendido por Max Weber, consiste em entender o sentido que as açð̋es de um indivíduo contém e não apenas o aspecto exterior dessas ações. Para se captar então essas açōes, Weber defendeu a utilização dos chamados 'tipos ideais' em rejeição à máxima positivista de que as metodologias da ciência natural e social são idênticas; a ciência social se preocupa mais com elementos subjetivos, fenômenos 'ideais'.

O 'tipo ideal', segundo Max Weber, expore como se desenvolveria uma forma particular de ação social se o fizesse racionalmente em direção a um fim e se fosse orientada de forma a atingir um e somente um fim. Assim,o 'tipo ideal' não descreveria um curso concreto de ação, mas um desenvolvimento normativamente ideal, isto é, um curso de ação teoricamente possível. O 'tipo ideal' é um conceito vazio de conteúdo real pois ele depura as propriedades dos fenômenos reais desencarnando-os pela análise, para depois reconstruí-los. Por conseguinte, o 'tipo ideal' não constitui nem uma hipótese nem uma proposição e, assim, não pode ser falso nem verdadeiro, porém válido ou não válido, de acordo com sua utilidade para a compreensão significativa dos acontecimentos estudados pelo investigador.

O 'tipo ideal', portanto, não é uma descrição de um fenômeno específico, mas uma construção que pode ser feita a partir das propriedades essenciais desse fenômeno integradas em um só modelo. Os elementos usados para elaborar esse modelo ideal são abstraídos de fontes diversas - períodos históricos diferentes e específicos. O modelo ideal de burocracia por exemplo, foi construído por Weber a partir de elementos comuns encontrados nas burocracias das sociedades feudal e capitalista; o método consistiu em comparar o tipo ideal de burocracia com uma forma real historicamente específica. 
A operacionalização do 'tipo ideal' pode ser feita de dois modos. O primeiro é o de fazer o contraste entre os fatos da realidade estudada e o modelo ideal. O segundo consiste na elaboração de hipóteses que possam explicar o fenômeno estudado. Por exemplo, para explicar a entropia no sistema de comunicação em uma organização qualquer, seria possível supor, em primeiro lugar, como funciona o processo de comunicação sem qualquer variável subjetiva, ou seja, a comunicação fluindo dentro das pautas de racionalidade estabelecidas formalmente. Feita esta abstração, se introduz hipoteticamente conteúdos subjetivos para aí encontrar a possível disfuncionalidade no sistema de comunicação.

Neste exemplo verificamos então que o 'tipo ideal' weberiano é exercitado com duas variáveis - a racionalidade e a irracionalidade, onde a racionalidade, segundo Weber, é também dependente de duas condições. Uma ação seria racional, em primeiro lugar, na medida em que fosse orientada para um objetivo claramente definido; e uma ação seria racional, em segundo lugar, quando os meios escolhidos e utilizados para atingir os objetivos propostos fossem os mais adequados para aquela racionalidade.

Então, para se compreender uma determinada ação burocrática, o pensamento weberiano torna-se indispensável. Para tanto, é necessário conhecer o 'tipo ideal' de burocracia que originou-se dos três tipos ideais de autoridade estabelecidos por Weber: autoridade tradicional, autoridade carismática e autoridade burocrática; cada categoria dessas correspondendo também a um tipo ideal de sociedade: tradicional, carismática, racional ou burocrática.

a) Autoridade tradicional, a legitimação do poder provém do passado e se baseia no costume de se fazer as coisas.

b) Autoridade carismática, o líder justifica a sua autoridade por meio de sua capacidade. A organização administrativa desse tipo é instável e indeterminada.

c) Autoridade legal ou racional, as leis são obedecidas e estabelecidas através de procedimento legitimado. A organização administrativa correspondente é a burocrática, que se caracteriza na aceitação das leis e na ordem legal.

As características do 'tipo ideal' de burocracia weberiano são as seguintes:

a) tarefas orientadas por normas escritas;

b) sistematização da divisão do trabalho;

c) cargos estabelecidos de forma hierarquizada;

d) regras e normas técnicas fixadas para o desempenho de cada cargo;

e) seleção de pessoal feita através do sistema de mérito; f) separacão entre propriedade e administração;

g) necessidade de recursos livres de controles externos para garantir a liberdade da organização;

h) profissionalização dos participantes; e

i) previsibilidade do comportamento dos seus membros.

A descrição weberiana de burocracia é por conseguinte perfeita já que define o fenômeno burocrático e ao mesmo tempo diz o que ele não é. Essa atitude constitui, junto com a intencionalidade na eliminação dos juízos de valor, sua grande colaboração ao tema. 
6. WEBER, Max. Ensaios de sociologia e outros escritos. Os Pensadores, São Paulo, Abril Cultural, v. 37, p. 22-3, 1973.
A validade do 'tipo ideal' de burocracia foi objeto de análise por parte de diversos autores. Tal análise foi realizada partindo-se muitas vezes de realidades e metodologias distintas. Naturalmente não foi aceito por todos, na medida que tais enfoques, em confronto com o 'tipo ideal', não refletiam com exatidão o fenômeno real estudado. A partir desse momento passa a existir por um lado a burocracia weberiana e por outro o que não é burocracia, esquecendo-se com isso que a preocupação de Max Weber foi a de elaborar uma ação 'objetivamente possível'. Tal perspectiva é referencial no sentido de que encontraremos, sempre, em qualquer que seja o ambiente em que atuemos, a predominância de grupos secundários formalizados, onde as características do modelo weberiano serão encontradas com maior ou menor rigor. Textualmente assim Weber referiu-se ao caráter universal do fenômeno burocrático:

“... O Estado democrático, assim como o Estado absoluto, elimina a administração feudal, patrimonial, patrícia, ou de outros dignitários que exercem o poder de forma honorária ou hereditária, e a substitui por funcionários civis. São estes que tomam as decisర̃es sobre todos os nossos problemas e necessidades diários... A mesma tendência burocrática predomina nas grandes empresas privadas de nossa época, na razão direta de seu tamanho, isto é, quanto maior for a empresa, maior será a burocracia que a envolve...

É simplesmente ridículo que nossos literatos creiam que o trabalho não manual no escritório privado é diferente, um mínimo que seja, do trabalho numa repartição pública. Ambos são basicamente idênticos."6

Conceituaçס̃es outras foram estabelecidas para divulgar a existência do mesmo fenômeno. No entanto, podemos dizer que não há uma burocracia típica, mas diferentes burocracias que correspondem a realidades históricas e sociais distintas. Diante da realidade organizacional de um país em desenvolvimento relativo, por exemplo, não temos de preocupar-nos se aquela realidade se ajusta ou não ao modelo organizacional de um país desenvolvido. Tanto em uma situação como na outra o que existe são sistemas burocratizados. Seriam então fenômenos distintos? Diferentes, claro, porém não originais: há um fundo comum, um 'tipo ideal', que depende de exigências sociais diferentes. Cada sociedade estuda ou tem problemas e respostas diferentes. Entretanto, todas são, por assim dizer, respostas burocráticas ou provocadas em sistemas burocratizados.

Isso posto, carece de sentido que nosso objeto de estudo os sistemas sociais organizados - sejam vistos de modo atomizado ou parcializado. Do mesmo modo não será indiferente a procedência acadêmica dos autores e suas perspectivas científicas. Pois onde existir interesse em identificar ou explicar situaçðes cujo fenômeno social será operacionalizado sob um sistema racional de decisర̃es, podemos dizer que há interesse pela burocracia ou de estudo do pensamento burocrático.

\section{As contradições da burocracia; conclusão}

A burocracia é um lugar de contradiç̃es e para concluirmos nada melhor do que apresentando possíveis paradoxos em seu movimento do ideal à prática. 
O fenômeno burocrático convive com aspectos dos mais contraditórios. É ao mesmo tempo a encarnação do bem e do mal, da eficiência e da ineficiência, da liberdade e do autoritarismo. No entanto, quando se contempla sem preconceitos a realidade, todas essas contradiçס̃es parecem lógicas e ainda necessárias. A razão fundamenta-se no fato de a burocracia ser um fenômeno social, onde fatores incidentes podem produzir conseqüências diferentes e inclusive opostas. A ambigüidade é, pois, nota essencial da burocracia. Há que se considerar tal fato sob pena de abordar unilateralmente um fenômeno necessariamente interdisciplinar e universal.

Nesta conclusão relacionaremos três contradiçø̃es inerentes à burocracia, sem com isso esgotarmos o elemento essencial de qualquer momento social. A primeira é que a organização burocrática surge sempre objetivando alcançar eficiência técnica. Isso, efetivamente, ocorre; porém não há como evitar que o tempo degenere técnicas burocráticas em rotinas disfuncionais. A técnica burocrática alcança desta maneira dois efeitos contrários: a eficiência e a ineficiência. Dizendo de outra maneira, a burocracia é um modo de gestão mais eficiente do que os anteriormente conhecidos (tradicional e carismático) não evitando contudo, por si mesma, a ineficiência.

A segunda é a de que a burocracia tem tido sempre um significado político: alguns indivíduos se servem dela para afirmar-se no poder. E, no entanto, a burocracia tende a abandonar sua condição instrumental e a apoderar-se diretamente do poder, suplantando às vezes o próprio dirigente.

A terceira contradição é a de que o burocrata é idealmente, um servidor que carece de interesses pessoais, consagrado que está ao serviço da burocracia ou da coletividade. Não obstante, os cargos burocráticos são ao mesmo tempo o meio de vida do burocrata e o meio também para desviar as energias organizacionais em proveito próprio.

Tais contradições são conseqüência da complexa estrutura burocrática. Normalmente se fala da burocracia como um bloco, e do burocrata como um tipo social homogêneo, quando na realidade esse possível bloco é constituído de elementos heterogêneos, freqüentemente opostos entre si por razão de interesses divergentes. Sem esquecer das diferenças resultantes das variedades históricas, culturais e funcionais não só da própria estrutura burocrática, como da própria sociedade onde está inserida.

Portanto, não é a burocracia o elemento exclusivamente distorcido de nossa sociedade. É a sociedade ou aqueles que a comporem ou dirigem que a deformam. Tal afirmação fica mais patente se, ao discutir um dado fenômeno burocrático, tivermos a mesma preocupação que teve Max Weber de desenvolver nossos estudos a partir de um marco referencial que globalize de modo 'ideal' características e padrőes de estruturas racionalmente organizadas. $E$ que aceitemos suas contradiçð̋es como elemento motivador de nova proposição organizacional. Proposição que deverá estar dependente não apenas de uma só teoria do fenômeno burocrático, mas também integrar as diversas teorias sabendo no entanto que a boa proposição de hoje não o será amanhã.

Por fim, diremos que o objetivo desse texto, apesar de o título 
levar o leitor a assim pensar, não foi o de perpetuar nem engrandecer o papel que tem Max Weber nas chamadas ciências sociais. Tentou-se mostrar em pouco espaço o quão 'ridículo' (palavra do próprio Weber) ficam aqueles autores, professores ou técnicos que, divulgando ou exercitando parcialmente o estudo da burocracia, deseducam leitores, estudantes ou clientes. Deseducam por não estarem aptos conceitualmente no que se refere ao fenômeno burocrático. Quando dizemos aptos conceitualmente, não é no sentido de estudar o fenômeno burocrático apenas com a ótica weberiana. A nossa idéia básica é a de que devemos estudar a burocracia e suas manifestações, partindo das diferentes concepçð̃es que a ela se reportam. Daí porque iniciamos focalizando, sem esgotar, as perspectivas liberal e marxista. A preocupação de centrar em Max Weber foi somente a de, por aceitarmos seu modelo como referencial, darmos um caráter mais científico ou imparcial ao tema burocracia. Sem descartar a hipótese de que a neutralidade do conhecimento e sua prática é dependente de conteúdo ideológico.

\section{Bibliografia}

1. CAMPOS, Edmundo, Sociologia da burocracia. 4. ed. Rio de Janeiro, Zahar, 1978.

2. CHIAVENATO, Idalberto. Teoria geral da administração. São Paulo, McGraw-Hill do Brasil, 1979, v.2., p. 7-55.

3. CROZIER, Michel. Subdesenvolvimento, administração e burocracria. Revista de Administração de Empresas, Rio de Janeiro,3(9): 117-34, out./dez. 1963.

4. El s.d. El fenómeno burocrático. Buenos Aires, Amorrortu Editores,

5. DESSLER, Gary. Organización y administración, enfoque situacional. Madrid, Editorial Dossat, 1979. p. 30-4.

6. ETZIONI, Amitai. Organizaçס̋es modernas. São Paulo, Pioneira, 1972. Cap. V, p. 81-92.

7. LAPASSADE, Georges. Grupos, organizaciones y instituciones. La transformación de la burocracia. Barcelona, Granica Editor, 1977. Cap. III, p. 107-212.

8. . Las nociones de estructuras y génesis. Buenos Aires, Ediciones Nueva Visión, 1975. p. 91-112.

9. McGUIRE, Joseph W. Teorias del comportamiento empresario. Buenos Aires, Editorial El Ateneo, 1974. Cap. II, p. 35-6.

10. MICHELS, Robert. Los partidos políticos - un estudio sociológico de las tendencias oligárquicas de la democracia moderna. 2. ed. Buenos Aires, Amorrortu Editores, 1972. v. I e II.

11. MOTTA, Fernando C. Prestes. As organizaçひes burocráticas e a sociedade. Educação e Sociedade, São Paulo, Cortez \& Moraes/ CEDES, 1(4):63-78, set. 1979.

12. Teoria geral da administração - uma introdução. 7. ed. São Paulo, Pioneira, 1979. Cap. 4, p. 53-72.

13. MOTTA, Fernando C. Prestes \& PEREIRA, Luiz C. Bresser. Introdução à organização burocrática. São Paulo, Brasiliense, 1980. Introdução p. 9-14; Cap. I, p. 15-55; Cap. V p. 167-98; Cap. VI, p.

199-221; Cap. VII, p. 222-41; Cap. X, p. 295-310.
14. NOUGUEIRA, Marco Aurélio. Max Weber: a burocracia e as armadiIhas da razão. In: TEMAS de ciências humanas, São Paulo, Editorial Grijalbo, 1977. n. 1. 
15. POULANTZAS, Nicos. Poder político y clases sociales. Barcelona, s. ed. 1972.

16. SCOTT, William G. \& MITCHELL, Terence R. Sociologia de la organización. Buenos Aires, Editorial El Ateneo, 1978. p. 7-8.

17. SEXTON, William P. Teorias de la organización. México, Editorial Trillas, 1977. Cap. 3, p. 51-6.

18. SILVA, Mario Martínez et alii. Dicionário de politica y administración pública. México, Colegio de Licenciados en Ciencias, Políticas y Administración Pública, s.d. p. 179-202.

19. SWINGEWOOD, Alan. Marx e a teoria social moderna. Rio de Janeiro, Civilização Brasileira, 1978. p. 64-8.

20. TRAGTENBERG, Maurício. Burocracia e ideologia. São Paulo, Ática, 1974. Cap. I, p. 21-57; Cap. III, IV e V, p. 93-219.

21. WEBER, Max. Ensaios de sociologia. Rio de Janeiro, Zahar, 1971. Cap. III, p. 68-73; Cap. VIII, p. 229-82. 


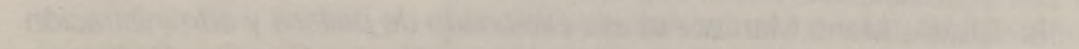

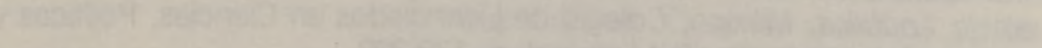

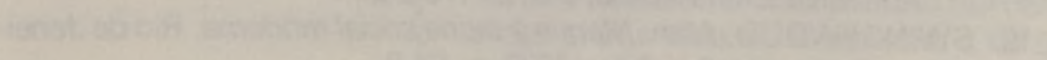

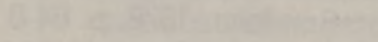

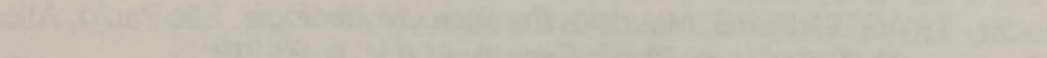

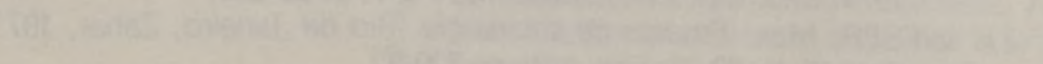
. 